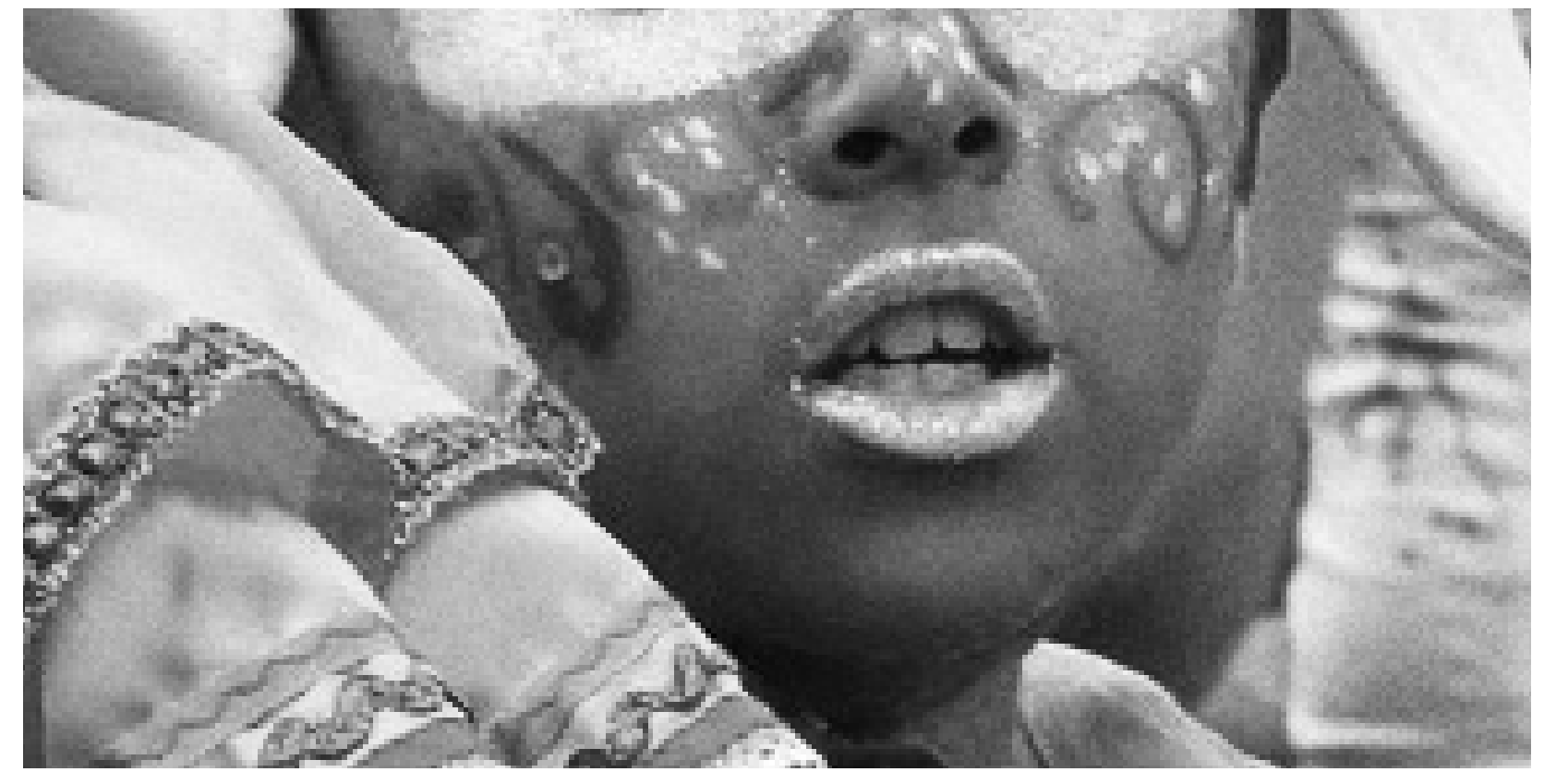

\title{
LA INVESTIGACIÓN Y FORMACIÓN DE PROFESIONALES EN RECREACIÓN EN EL CAMPO DE LO FESTIVO.
}

THE RESEARCH AND TRAINING OF RECREATION PROFESSIONALS IN THE FESTIVE. 
Resumen: El artículo presenta el trabajo que desde el Programa Académico de Recreación de la Universidad del Valle se viene realizando en la formación de sus profesionales en el campo de lo festivo. Para esto desarrolla al menos cuatro tareas. La primera tarea sitúa tres experiencias a partir de las cuales se deriva la reflexión (desde la docencia, la creación de procesos de trabajo con estudiantes y desde la investigación). Una segunda tarea ubica lo festivo en el campo de la recreación como actividad social general y como proceso educativo (Mesa, 1997). La tercera tarea presenta algunas nociones teóricas, repertorios y técnicas del Curso Historia de la Recreación II en la formación teórica, metodológica y vivencial en el campo de lo festivo. Por último, se presentan algunas reflexiones y resultados producto del trabajo de formación en este campo.

Palabras claves: Recreación/Educación, Fiesta/Carnaval, Formación Profesional, Diseño/Creación.

Abstract: The article presents the work that is carried out in the training of its professionals in the field of the festive from the Academic Program of Recreation of Valle University. For this purpose, the program develops at least four tasks. The first task places three experiences from which the reflection is derived (from teaching, the creation of work processes with students and from research). A second task places the festive in the field of recreation as a general social activity and as an educational process (Mesa, 1997). The third task presents some theoretical notions, repertoires and techniques of the History of Recreation Course II in the theoretical, methodological and experiential formation in the festive field. Finally, some reflections and results are presented as a product of the training work in this field.

Keywords: Recreation/Education, Party/Carnival, Vocational Training, Design/ Creation.

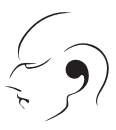

\section{A modo de introducción}

El presente artículo se deriva de tres experiencias particulares desde las cuales se ha venido pensando la relación Fiesta/Carnaval y Recreación/Educación, en la formación de profesionales en Recreación de la Universidad del Valle. 
La primera experiencia, corresponde al trabajo como docente en el curso Historia de la Recreación $I I^{2}$ en el cual se presenta lo festivo como campo de estudio ${ }^{3}$.

La segunda experiencia, se sitúa en el diseño y creación de un proyecto de viaje denominado Grupo de Estudio Nómadas ${ }^{4}$. Este ejercicio emerge de una fase de experimentación docente por diseñar y crear asignaturas que hicieran un entrecruzamiento entre los componentes de formación conceptual, metodológico y vivencial. Han sido propósitos del Grupo estudiar las fiestas y carnavales en Colombia y América Latina, vinculados al diseño y creación participativa de rutas, por parte de los estudiantes.

La tercera experiencia corresponde a la investigación Recreación/Fiesta y Educación: Un estudio del carnaval de Riosucio como experiencia recreativa y organizativa (Henao, 2012a $)^{5}$. Este proyecto de investigación se ocupó del estudio de lo festivo desde dos dimensiones de la Recreación: la primera, como actividad social general y la segunda, como proceso educativo (Mesa, 2008; Mesa. e., 2011). Para ello, se seleccionó el Carnaval de Riosucio como objeto empírico con el fin de comprender la dimensión educativa del carnaval mediante el estudio de sus formas recreativas y organizativas (Henao, 2012a).

A partir de las anteriores experiencias de trabajo en investigación y formación, el presente artículo presenta algunas rutas que se han configurado para pensar la formación e investigación de profesionales en el campo de lo festivo.

\section{El Campo de lo festivo en el Programa Académico de Recreación.}

"Al delimitar el ámbito problemático de lo festivo, partimos de suponer que la fiesta es un tipo de práctica recreativa diferenciable de lo específicamente lúdico aunque lo contiene y sea una de sus propiedades constitutivas (...). En especial nos interesa la fiesta popular y carnavalesca, los lenguajes lúdico creativos que median la externalización e internalización de las formas de resistir e impugnar un orden determinado y establecido, especialmente los procesos de organización de las fiestas populares” (Mesa e, 2005:.5).

Vamos a entender la fiesta como una práctica social y recreativa; como un campo de intervención e investigación para los profesionales en recreación. Lo festivo es desde esta perspectiva una categoría de análisis en la que convergen distintas formas y maneras de ser de la fiesta. El libro La fiesta, la otra cara del patrimonio (Pizano, 2004) propone que gran parte del "universo festivo en América Latina es producto de la interrelación de festividades religiosas católicas traídas por los españoles, que a su vez tenían origen en arcaicos ritos precristianos del Viejo Mundo, ceremoniales, aborígenes, prehispánicos y ritos seculares africanos" (22). Los autores proponen una tipología de estas fiestas atendiendo a los siguientes parámetros: carácter o propósito de la celebración; el ser u objeto celebrado; la colectividad que celebra y la dota de sentido; agente u órgano de gestión que la organiza. Así se constituyen 
cuatro grandes categorías: 1) fiestas; 2) festivales; 3) ferias y 4) carnavales. La fiesta en la Edad Media, por ejemplo, comprendía una categoría de las formas y rituales del espectáculo y como manifestación de la risa en el marco dela Cultura Cómica Popular (Bajtin, 1990; Henao, 2012).

En el caso de los Programas de Tecnología y Profesional en Recreación de la Universidad del Valle lo festivo es un campo de estudio que forma parte de los problemas al interior de la malla curricular y dentro de las preguntas de formación. Interesa el estudio de lo festivo, en tanto práctica recreativa y popular, que emerge en las construcciones sociales y colectivas, por orígenes políticos, religiosos, culturales. La fiesta es una oportunidad para "identificar las potencialidades de la recreación en la vigencia actual de la fiesta popular" (Mesa G. 2001, p. 6) como un problema de la recreación se puede analizar desde distintas dimensiones, como actividad social general y la recreación como proceso educativo (Mesa, 1997).

Es a partir de estas dos dimensiones que se establecen dos premisas para pensar la relación Recreación/Educación-Fiesta/Carnaval (Henao A. \&., 2019):

\section{Premisa 1: Lo festivo en la Recreación como actividad social general}

De acuerdo con Mesa (2004) la recreación como campo de conocimiento se puede estudiar desde tres dimensiones: a) la recreación como actividad social general; b) la recreación como proceso educativo; y c) la recreación como actividad interna (psicológica). Desde la primera dimensión, la recreación, es una actividad importante en la vida de los sujetos y en la construcción de su relato histórico. Esta se configura de manera relacional con otras dos actividades igualmente centrales en la vida humana: el trabajo y la educación. La recreación, el trabajo y la educación se presentan como una constante en las distintas etapas del desarrollo humano y social, aun cuando en una etapa se puede hablar de una actividad predominante sobre las otras (por ejemplo el trabajo en la edad adulta), es esta relación dialéctica entre las tres la que modela la experiencia social (Mesa, 1997).

Desde esta dimensión es importante destacar toda la investigación de la profesora Guillermina Mesa (Universidad del Valle) -a nivel teórico y metodológico- y quien ha trabajado alrededor de la discusión y refinamiento de cuatro problemas de estudio. Los Lenguajes Lúdico-Creativos, lo Contemplativo, lo Lúdico y lo Festivo. (Mesa, 1997; Mesa e, 2008). Estos núcleos se plantean como objeto de estudio -para quien se interesa en la reflexión de la recreación como mediación social para la construcción simbólica y de sentidos- para comprender el reconocimiento de las potencialidades de la actividad recreativa y su influencia en los procesos

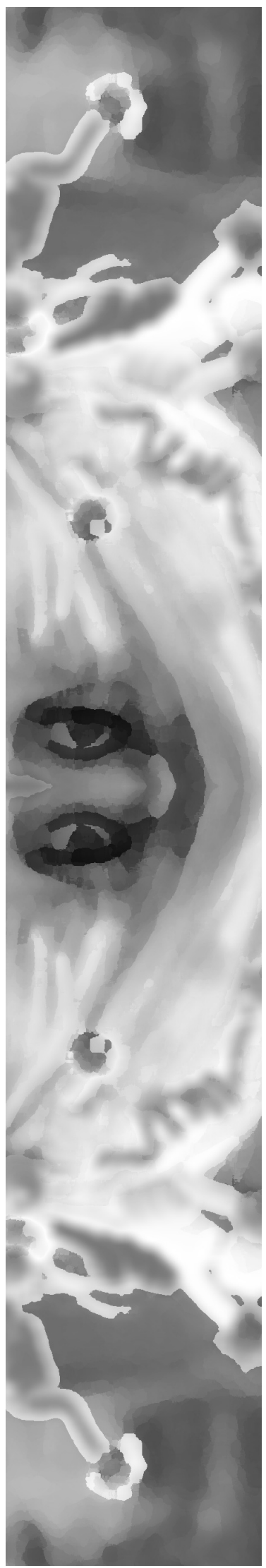


de cambio y transformación socio-cultural, en la emergencia de construcciones populares creativas de resistencia, impugnación, hibridación cultural, resignificación y búsqueda de nuevos sentidos. Es importante subrayar que en las prácticas recreativas estos núcleos no operan como problemas independientes o excluyentes entre sí. Así, el estudio de lo festivo anclado a lo recreativo, no desconoce los aspectos lúdicos y contemplativos que también convergen en las experiencias de fiesta.

El estudio de lo festivo vinculado por ejemplo al estudio de los carnavales es importante entender: a) la condición histórico/cultural en la que emergen; b) los sucesos, las situaciones y eventos que impugnan; es decir, los aspectos que se critican y a los que se hace una resistencia política y social (De Certeau, 2000; Martín Barbero, 1987); c) las consignas o ideas que se quieren proclamar, reivindicar, recrear, resignificar a través de los lenguajes del carnaval, d) como las fiestas y carnavales operan como recurso (Yúdice, 2002); en otras palabras, cómo pueden ser una mediación pedagógica para potenciar formas de encuentro, vínculos sociales (González, 2000), (Gómez \& Gónzalez, 2005), procesos de negociación grupal, saberes y las habilidades de los participantes, formas de impugnar, proclamar, experiencias estéticas que permitan subvertir ordenes, jerarquías, en escenarios formales de enseñanza y aprendizaje.

\section{Premisa 2: Lo festivo en la recreación como proceso educativo}

Concebida desde la perspectiva de la Influencia Educativa (Coll, 1985, 1988), la recreación se configura como un proceso de enseñanza-aprendizaje de doble vía que. aunque no corresponde a los procesos formales de educación escolar, establece un símil entre los actores del aprendizaje escolar porque supone: a) un educador que ejerce como recreador, b) estudiantes que ejercen como recreandos y c) unos contenidos/tareas desde los cuales se medía la situación educativa Estas tareas y contenidos se caracterizan por ser de naturaleza festiva, lúdica y construyen problemas del orden de lo cognitivo-conceptual, procedimental -creativo- y de lo actitudinal-socioafectivo (Mesa, 1997, 1998, 2004).

Las experiencias recreativas estudiadas desde esta perspectiva requieren ser pensadas en un contexto determinado y una franja de tiempo específico en el que sea posible observar cómo emergen las reiteraciones, las discontinuidades, las transformaciones en las responsabilidades y el dominio sobre los contenidos culturales, el lugar que ocupan los recreandos y recreadores en esa situación educativa, las resignificaciones y apropiaciones que logran realizar sobre conceptos y contenidos concretos (Mesa G. \&., 2008)

La fiesta como experiencia recreativa construye unas motivaciones e intencionalidades susceptibles de permanecer y transformarse en el tiempo. Así es como desde esta mirada del carnaval -como proceso educativo (no escolarizado)- se parte de suponer que se produce un cierto tipo de influencia educativa en la que a través del tiempo 
los distintos actores enseñan y aprenden en un proceso de doble vía. Interesa en esta perspectiva comprender cómo se asumen, se traspasan (en el proceso de inter-actividad festiva) y se resignifican las distintas tareas por parte de los actores. Por otro lado, pensar, por ejemplo, el carnaval de Riosucio desde sus formas organizativas atendiendo a la perspectiva de Goffman (1959), permite reconocer en clave de una cierta "teatralidad" y desde las "actuaciones sociales" las formas y el tipo de agenciamiento de lo recreativo, de lo político, de las formas de recreación y resignificación del orden social que se establece en un proceso de interacción como este.

\section{Algunas nociones teóricas en el marco del curso Historia de la Recreación II}

Las fiestas son construcciones míticas simbólicas en las que se manifiestan las creencias, mitos, concepciones de la vida y del mundo, y los imaginarios colectivos y están asociadas a algunas etapas del ciclo vital, de la economía, de las creencias religiosas, de la política y de otras motivaciones humanas. (Pizanoetal 2004)

\section{La inversión del mundo}

Las Saturnales Romanas ocurrían el 17 de diciembre en el Imperio Romano, cuando cesaba la época de cosecha y llegaba la época de descanso. Uno de los elementos simbólicos más importante consistía en el intercambio de ropajes. Los esclavos intercambiaban con sus “amos" sus ropas significando que los primeros tomaban el poder y la jerarquía de mando.

Era una festividad en la que el mundo se ponía al revés; los esclavos manifestaban sus incomodidades y los amos escuchaban y servían durante este período festivo. Este principio, el del mundo al revés, se convierte en un punto de partida para revisar el tema de “la inversión” en el carnaval y la fiesta. El mundo normalizado, oficial, con establecimiento de jerarquías, cesa sus lógicas y lo que en esa escala de valores no es tenido en cuenta, es ocultado o avergonzado, cobra un nivel superior, se torna central y vital ${ }^{6}$.

\section{Cruzar el umbral. Del mundo oficial al mundo del carnaval.}

¿Qué significa cruzar el umbral? "Umbral, límite entre dos espacios, donde los principios antagónicos se enfrentan y donde el mundo se invierte. Los límites son lugares de lucha: límites entre los campos que son el lugar o la ocasión de luchas" (Bourdieu 1991, pps. 337, 360). Una de las características de las distintas fiestas y carnavales en la Edad Media era la construcción de una clara dualidad de mundo. Frente al mundo oficial, se construía un mundo no oficial y en este, la fiesta, la Cultura Cómica Popular, eran la centralidad, la razón de ser. Esta segunda vida aparentemente sin sentido cobraba fuerza en oposición, como choque a una vida 
oficial cargada de racionalidad. Cruzar el umbral entonces significaba el tránsito entre dos espacios, del mundo oficial al mundo no oficial ${ }^{7}$. Una lucha por dos figuras mitológicas, Apolo (dios de la guerra y la razón) y Dionisio (dios de la fiesta y el caos). Lo "Apolíneo" representa el mundo oficial, el dios de la guerra, de la conquista, el éxito de un pueblo sobre otro, la vida seria, el deber ser, lo correcto. Lo “Dionisíaco”, entonces, representa el mundo no oficial, el sin sentido, lo carnavalesco y orgiástico, la no conquista de nada, el goce por el goce, la burla de ese mundo oficial.

Para Bajtin (1990) la vida en el carnaval, la vida en el Medioevo, tenía un aspecto filosófico muy importante. El mundo como una gran rueda que gira, lo que significa que en un momento esta vida que puede estar arriba, pasar por distintos lugares hasta estar abajo. De lo que nos habla entonces es de la eterna renovación a la que los pueblos y la humanidad nos exponemos constantemente. Por ejemplo, lo que un terremoto le pone a un pueblo, una condición de vida-muerte. Una crisis económica de un país pone una condición de fragilidad, obliga a reconocerse solidarios y a replantear una mirada sobre lo colectivo y no sobre lo individual. El carnaval se convierte entonces en una posibilidad de pensar el tema de la renovación. Un constante juego entre la vida- muerte, un cruce permanente de este umbral. Casi todos los carnavales de Colombia, por ejemplo, arrancan con la lectura de un "Bando de Carnaval"; este bando es escrito de manera burlesca, usando palabras y formas del lenguaje oficial pero re-creadas, mofándose y dando permiso al pueblo para entrar en estado dionisíaco. En el bando se expresa de manera carnavalesca los sentidos del carnaval, el por qué y se decretan todos los permisos y "restricciones" (una restricción puede ser "prohibido no reírse"). Esta entrada al mundo no oficial, esta entrada de renovación (con el nacimiento del carnaval) de igual forma es marcada con la idea de que lo que nace debe morir (la muerte aquí se presenta también como renovación), el carnaval debe morir, el pueblo no puede quedarse toda la vida en un estado de "sin sentido y festividad colectiva". Este momento casi siempre ocurre a través de una quema, el fuego que consume y da vida (sentido de renovación) y como la eterna rueda el mundo del carnaval da paso de nuevo al mundo oficial. El fuego es un elemento clave para simbolizar la muerte, pero la muerte como una posibilidad de dar vida a algo nuevo. Se supone que después de una experiencia de carnaval, de una experiencia intensa como esta a pesar de que se vuelva a la vida oficial, al mundo serio, ya nada será lo mismo ${ }^{8}$.

Lo Colectivo versus el espectáculo. Es importante acotar que Bajtin (1990) muestra en la Historia de la Risa como la idea de espectáculo sufre una transformación que va del espectáculo pensado para la plaza pública hasta llegar al espectáculo de consumo. En la actualidad algunas fiestas son para el pueblo sin el pueblo.

Esto sería lo que llamaríamos espectáculo en el que claramente se ve la diferenciación entre "actores" y "espectadores". Los actores preparan un espectáculo, una fiesta para ser vista por otros, los otros la ven, la disfrutan, se antojan, pero no hacen parte de ella. En la idea clásica del carnaval, no hay actores ni espectadores, "es el pueblo 
el que carnavalea”. Es una fiesta diseñada por el pueblo para sí mismo. Son actores y espectadores que juegan y danzan. El carnaval ocurría en la plaza pública, en la que el pueblo se conjugaba, bailaba, hacía acrobacias con los saltimbanquis, participaba de los decretos, de los actos circenses, etc. En el proceso de discusión del curso y de la puesta en escena de los ejercicios de clase, uno de los errores en los que suelen caer con mayor frecuencia los estudiantes de recreación es la de hacer una mirada del carnaval como arte, como espectáculo, construyen talleres en los que sus compañeros son simplemente espectadores del taller, les preparan una danza en la que los encargados del taller bailan y sus compañeros ven y los aplauden; en otras situaciones ponen a hacer todo a los estudiantes y los encargados del taller se convierten en meros espectadores y directores. Para el Programa de Recreación lo festivo no es mirado como espectáculo o como fiesta privada, su riqueza radica en su capacidad de hacer partícipe a los sujetos, construir un proyecto de trabajo y un estilo de vida, nos interesa su carácter popular y abierto, la re-significación de las estéticas, lo que potencia de creativo y colectivo. Para este punto es importante que los recreadores(as) se piensen una propuesta en la que gran parte del trabajo se desarrolle de manera colectiva entre los recreadores y los recreandos.

El carácter lúdico de nuestras propuestas. Cuando jugamos, todos participamos de la creación y la ejecución del juego en distintos niveles, algunos juegan, el otro dirige el juego, otros están a cargo de que se cumplan las reglas del juego, pero cada uno desde su lugar participa en él. En este punto es importante pensar que a través del juego podemos simbolizar, representar y burlarnos también del mundo oficial. En el Medioevo, como lo plantea Bajtin (1990), una manera de burlarse y exorcizar la guerra era cogerse a porrazos, jugar y tirarse excrementos humanos $^{9}$. El juego en el carnaval ocurre para sus participantes como una manera de integrarse a su universo. Para Bajtin (1990), el carnaval está situado entre la vida y el arte. En el caso de la investigación sobre el Carnaval de Riosucio (Henao \& Sánchez, 2019) este ejercicio ocurre entre el arte y el juego. Es decir que entre las formas organizativas del carnaval y las formas recreativas del carnaval emerge la dimensión educativa de la fiesta y la recreación como proceso educativo.

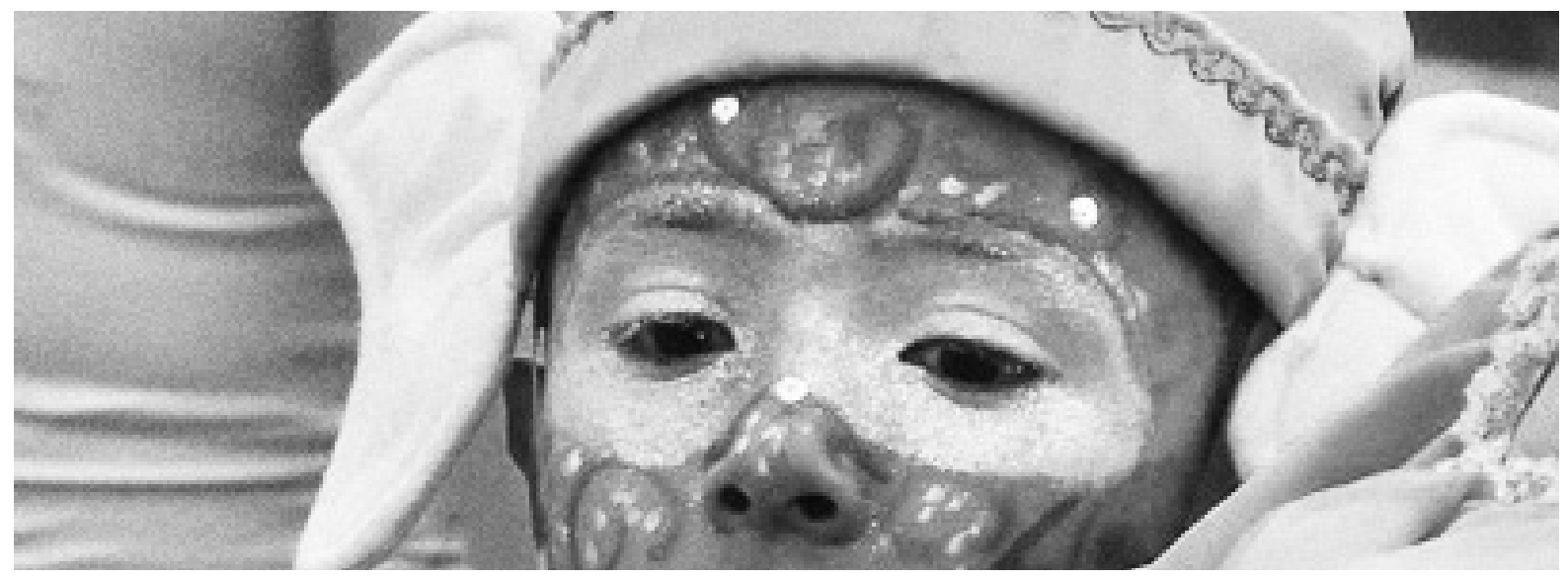


A continuación, se presenta un cuadro síntesis en el que se establecen algunas preguntas de trabajo en el curso para pensar los procesos de diseño y creación de actividades festivas:

Tabla 1. Pistas teóricas y consideraciones para el Diseño y Creación de proyectos festivos.

\begin{tabular}{|c|c|}
\hline Pista/Nociones Teóricas & $\begin{array}{l}\text { Consideraciones y preguntas para la reflexión, } \\
\text { diseño y creación de proyectos festivos. }\end{array}$ \\
\hline $\begin{array}{l}\text { Inversión. } \\
\text { Los estudiantes tienen la tarea de aprender a invertir } \\
\text { valores, nociones, maneras cotidianas del grupo. } \\
\text { Poner el mundo al revés. Trabajar la dualidad y } \\
\text { ambivalencia como condiciones de lo festivo. }\end{array}$ & $\begin{array}{l}\text { a) ¿Cuáles son las inversiones a proponer en sus } \\
\text { talleres sobre Carnavales? } \\
\text { b) ¿Cómo trabajar desde los asuntos cotidianos de su } \\
\text { vida personal y académica este tema de la inversión? } \\
\text { c) ¿Cuáles son los elementos de dualidad y } \\
\text { ambivalencia que se pueden trabajar desde la fiesta o } \\
\text { carnaval estudiado? }\end{array}$ \\
\hline $\begin{array}{l}\text { Umbral/vida-muerte/renovación. } \\
\text { Esta concepción sociológica y filosófica tiene como } \\
\text { tarea pensar las condiciones de umbral (entrada- } \\
\text { salida) que contienen los distintos procesos festivos. } \\
\text { La condición de vida, muerte y las condiciones de } \\
\text { renovación que emergen en este tránsito. }\end{array}$ & $\begin{array}{l}\text { a) ¿Cómo vamos a marcar en nuestros talleres de } \\
\text { carnaval el paso de la vida seria (oficial) al mundo no } \\
\text { serio (vida de Carnaval)? } \\
\text { b) ¿Qué elementos de renovación (vida-muerte) } \\
\text { trabaja nuestro carnaval a estudiar? } \\
\text { c) ¿Cómo vamos a trabajar el paso de la vida de } \\
\text { Carnaval a la vida oficial? }\end{array}$ \\
\hline $\begin{array}{l}\text { Lo colectivo vs el espectáculo. } \\
\text { Aquí es clave trabajar sobre una condición } \\
\text { importante: la construcción de un diseño en el que } \\
\text { los estudiantes se sientan integrados, no sean actores } \\
\text { ni espectadores sino que transiten por ambos roles. } \\
\text { Aquí es clave pensar la noción de risa renovadora } \\
\text { versus burla satírica trabajada durante el curso. Este } \\
\text { aspecto es uno de los que más cuesta trabajo de } \\
\text { materializar en el diseño de las propuestas festivas } \\
\text { que los estudiantes presentan. }\end{array}$ & $\begin{array}{l}\text { a) ¿Cómo diseñar un taller recreativo sobre } \\
\text { carnavales en la que todos participemos, en la que } \\
\text { todos seamos actores y espectadores? } \\
\text { b) ¿Cómo mantener el carácter de lo público, de } \\
\text { carnaval para el pueblo y no como un espectáculo de } \\
\text { consumo? } \\
\text { c) ¿Cuáles son los elementos a diseñar para que } \\
\text { ocurra la risa colectiva (renovadora)? }\end{array}$ \\
\hline $\begin{array}{l}\text { Lo Festivo/Lo Lúdico. } \\
\text { El estudiante debe trabajar en sus grupos la línea } \\
\text { que propone Bajtin (1990) entre la vida y el arte. } \\
\text { En este caso combinar una propuesta festiva pensada } \\
\text { desde la recreación como actividad social general, la } \\
\text { recreación como proceso educativo en la que la fiesta } \\
\text { contiene un fuerte componente lúdico. }\end{array}$ & $\begin{array}{l}\text { a) ¿Cuál va a ser nuestra propuesta festiva y lúdica en } \\
\text { los talleres de Carnaval? } \\
\text { b) ¿Cómo integrar todos los elementos de reflexión } \\
\text { para que nuestras experiencias festivas no queden en } \\
\text { el mero espectáculo o entretenimiento? }\end{array}$ \\
\hline
\end{tabular}




\section{Repertorios y técnicas del curso Historia de la Recreación II.}

- Trayectorias Biográficas. La historia de todos los ombligos festivos (Técnica Bandas Gráficas) y la fiesta y el ombligo colectivo (Técnica Murales). En esta ruta de trabajo asumimos que lo bio-gráfico es una herramienta de investigación que nos permite reflexionar "sobre lo que desconocemos de nosotros mismos" y creemos saber, pero también damos cuenta de la historia de un país, de una ciudad, de la manera de pensar de una sociedad en un momento específico. Nuestra historia individual es la historia también social (Gónzalez, 1999; Henao, 2008). Este taller de trayectorias biográficas comprende dos momentos. El primero, la realización de bandas gráficas ${ }^{10}$ en la que cada estudiante expone cuáles han sido los momentos más importantes y los aprendizajes festivos en su vida, luego los estudiantes construyen una propuesta gráfica en la que intentan plasmar las semejanzas y diferencias encontradas en los pequeños grupos. El segundo momento comprende un ejercicio colectivo en la construcción de ejercicios de síntesis sobre obras expresivas en las que sintetizan los hallazgos de las presentaciones a través del técnica graficoplástica de mural. Con estos dos ejercicios se avanza a la construcción de máscaras a través de la técnica de vendas de yeso y vaciado.

- Construcción de máscaras. Técnica Vendas de Yeso y Vaciado. En este taller se busca trabajar el concepto de Lenguaje Lúdico (Mesa 2004) en la tarea de los Profesionales en Recreación y a su vez que aprendan un repertorio de Técnicas de cómo se trabajaría desde el diseño distintos temas. Previamente a este taller se ha realizado con los estudiantes un ejercicio denominado descarga visual ${ }^{11}$ en el que a través de imágenes se hace un recorrido por las principales estéticas, formas, colores y dimensiones de las máscaras en fiestas y carnavales del mundo, con el fin de motivar a los estudiantes en el diseño y construcción de su propia máscara festiva. Para el taller se organizan los estudiantes en grupos, se explica cómo el trabajo a realizar obedece a una cierta artesanía, trabajar sobre el rostro del otro, trabajar con sus miedos y resistencias frente a la técnica. Cada estudiante trabaja sobre el rostro de uno de sus compañeros y luego otro estudiante trabajará sobre el suyo. En términos del trabajo con jóvenes requiere trabajar sobre la ansiedad, la inmediatez, revisar con cuidado que se siga cada una de las instrucciones para no ir a tener ningún inconveniente en el momento de retirar la máscara del rostro. Generalmente, este trabajo está acompañado por estudiantes que ya han cursado la asignatura y apoyan y median en el proceso bajo la supervisión del docente. Terminado este proceso, cada semana se van entregando una serie de pautas para la realización de las fases siguientes. Se traza una pregunta de fondo para este diseño: ¿Qué significa para mí la fiesta contada desde el color, las formas, las texturas y los símbolos en mi máscara? En otras versiones del curso se ha usado el recurso de la máscara para preguntar cuáles son mis miedos y sueños frente al proyecto académico contada desde el color, las formas, las texturas y los símbolos en mi máscara. 
- El recreador como artesano. En este taller los estudiantes presentan los resultados de su primer ejercicio de diseño de máscaras en el que han trabajado desde el color, el diseño, la forma y la textura algunas preguntas sobre el papel que ocupa la fiesta en sus vidas y las potencialidades de la fiesta. Junto a este ejercicio se conversará sobre el papel del recreador como artesano en los procesos organizativos de las fiestas y el carnaval.

- Nuestras fiestas recreadas. En este taller los estudiantes tendrán que construir creativamente un ejercicio de síntesis en el que vinculen dos fiestas en las que el equipo de trabajo se sienta conectado o sientan que no fueron vividas en sus distintas etapas de desarrollo. Es así como puede aparecer la Fiesta de los Quince Años acompañando la Fiesta de Fin de Año. O un Matrimonio acompañado de una Primera Comunión.

- El Banquete de Platón. En este ejercicio los estudiantes trabajarán el concepto de "Estética" a través del proceso de construcción del "Eros en la Comida" Como conceptos claves estarán acá: Re-significar y Erotizar. Deben preparar banquetes que configuren para sus compañeros una "experiencia estética" desde lo visual, lo auditivo, el gusto, el tacto y el olfato.

- Diseño y construcción de una propuesta festiva a partir de las premisas trabajadas en el curso. Este ejercicio final del curso busca hacer un entrecruzamiento entre lo teórico, lo metodológico y lo vivencial. Por un lado, que los estudiantes indaguen cómo ocurren los elementos trabajados en el curso en una fiesta o carnaval específico pero también que hagan un ejercicio creativo por re-significar esta fiesta dotándola de elementos y particularidades del grupo con el cual se trabajará (en este primer momento con sus propios compañeros de clase). Es importante recordar que los recreadores(as) no son artistas ni reproductores de los procesos festivos y lúdicos, nuestra tarea es transformarlos en propuestas creativas que permitan a los recreandos aprender de sí mismos, de su entorno, de los otros, ser críticos, exorcizar sus temores y di-soñar el futuro de manera colectiva. Esta última ruta corresponde al enfoque pedagógico de la propuesta, permitir que los estudiantes a través de la fiesta se reconozcan como sujetos con potencialidades y capacidades en la vivencia de lo festivo.

- Exposiciones teóricas sobre los carnavales. Los estudiantes deben presentar su indagación conceptual e histórica sobre el carnaval o fiesta que luego trabajarán de manera práctica.

- Campamento y Narrativas Estéticas de Carnaval. De manera transversal, este curso estará vinculado a los procesos de formación de la Consejería Estudiantil. Allí los estudiantes durante las sesiones de trabajo los días martes de 10:30 a. m. a 1 p.m. estarán desarrollando distintas narrativas estéticas de carnaval: bando, comparsa, letras de carnaval, decretos, letanías, letras cuadrilleras, refranes, maquillaje y máscaras. Este ejercicio taller será presentado en un taller-campamento que cerrará el proceso vivencial de los estudiantes en Consejería Estudiantil.

A continuación, se presentará un cuadro con algunas de las preguntas a nivel conceptual, metodológico y vivencial que se van proponiendo a los estudiantes para el diseño de sus proyectos festivos finales: 


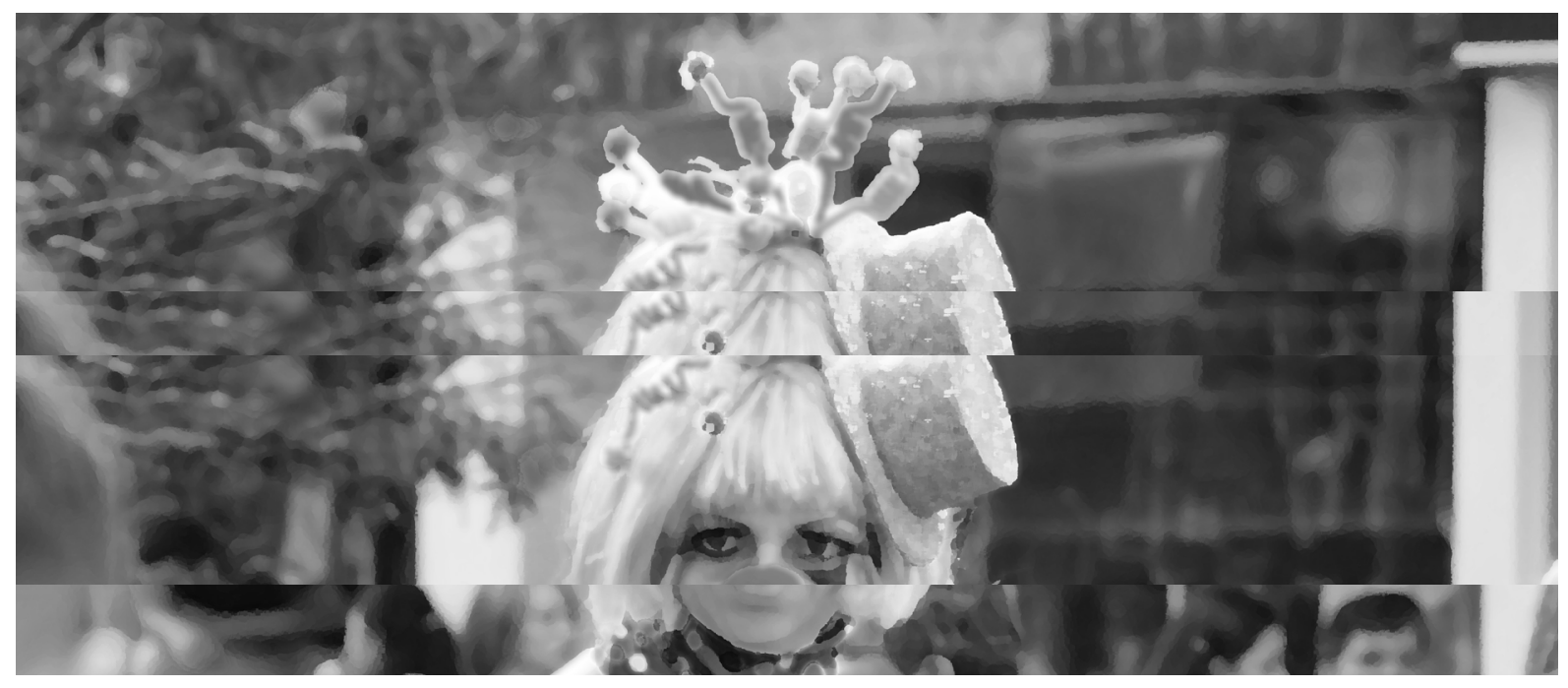

Tabla 2. Cuadro 1. Preguntas orientadoras para el entrecruzamiento: Teórico, Metodológico y Vivencial en el diseño y creación de un proyecto festivo en el marco del curso Historia de la Recreación II.

\begin{tabular}{|c|c|c|}
\hline A nivel Conceptual & A nivel Metodológico & A nivel Vivencial \\
\hline \begin{tabular}{|l} 
¿Cuáles son los orígenes, el \\
contexto social y político en el que \\
emerge la festividad estudiada? \\
¿Cuáles son los principales \\
momentos de la festividad \\
estudiada y qué representa cada \\
uno de ellos? \\
¿Cuáles son los principales \\
elementos simbólicos y estéticos \\
de la festividad estudiada? \\
¿Cuáles son los elementos de \\
inversión, renovación, burla a \\
los que hace alusión la festividad \\
estudiada? \\
¿Cuáles son los principales \\
actores/hacedores de la festividad \\
estudiada? \\
¿Cuáles son las principales \\
transformaciones que ha \\
experimentado la festividad \\
estudiada?
\end{tabular} & $\begin{array}{l}\text { ¿Cómo diseñar una propuesta } \\
\text { festiva que aproveche los distintos } \\
\text { hallazgos sobre la festividad } \\
\text { investigada y vincule los distintos } \\
\text { recursos y repertorios trabajados } \\
\text { durante el curso? } \\
\text { Para el diseño y creación de la } \\
\text { propuesta festiva ¿cuáles serán } \\
\text { y por qué los momentos que } \\
\text { seleccionarán de la festividad } \\
\text { investigada? } \\
\text { ¿Cómo se van a integrar los } \\
\text { elementos seleccionados de } \\
\text { juego, inversión, renovación burla } \\
\text { seleccionados de la festividad } \\
\text { investigada? } \\
\text { ¿Cuál es la apuesta creativa } \\
\text { y resignificadora a nivel } \\
\text { metodológico y vivencial? } \\
\text { A partir de los elementos estéticos } \\
\text { y simbólicos seleccionados de la } \\
\text { festividad investigada ¿cómo serán } \\
\text { integrados en su propuesta festiva? }\end{array}$ & $\begin{array}{l}\text { ¿Cuáles son los elementos } \\
\text { a nivel de vínculos sociales, } \\
\text { reconocimiento de habilidades } \\
\text { y potencialidades aspira trabajar } \\
\text { desde su diseño festivo? } \\
\text { ¿A nivel de trabajo en grupo, de } \\
\text { juego, cuáles son los aspectos } \\
\text { a potenciar desde el disfraz, la } \\
\text { máscara, bando? } \\
\text { ¿Qué elementos de seguridad } \\
\text { y cuidado se tendrán en cuenta } \\
\text { sabiendo que es un ejercicio que } \\
\text { trabaja catarsis colectiva? }\end{array}$ \\
\hline
\end{tabular}




\section{Reflexiones finales.}

Estamos, pues ante una sabiduría popular que ha comprendido que las adversidades naturales y las imposiciones sociales sólo se pueden afrontar en común y ritualizándolas (Maffesoli, 1996, pág. 19).

Estas son algunas reflexiones que se han ido construyendo producto de este ejercicio de investigación/reflexión sobre la tarea docente, investigativa y en extensión en la formación de Profesionales en Recreación en el campo de lo festivo:

La primera, el carnaval y la fiesta como núcleo de investigación e intervención. Una de las claves del carnaval para pensarlo en nuestro trabajo como recreadores(as) es comprenderlo como "un lenguaje" desde el cual es posible narrar, externalizar la experiencia de un colectivo frente a sus miedos, sueños, vivencias como grupo, sus guerras, sus victorias, sus opresiones y resistencias. Estamos diciendo entonces que a través del carnaval podemos reconocer asuntos de lo político, social y cultural en una experiencia colectiva. Igualmente, es importante pensar el carnaval como una propuesta en la que es clave: a) lo colectivo, b) lo lúdico, c) lo festivo, d) el disfraz y la máscara, como maneras de contar y representar esta externalización de la que hablamos.

Pensar los elementos antes mencionados es una posibilidad para contar y construir narrativas que subviertan el orden de los discursos oficiales de contar. Los carnavales son también una lectura de la idea- mundo de los pueblos contados desde el humor, la risa, la resistencia y una manera de pensar el mundo cuando se pone al revés. Aquí es posible poner nuestras fantasías, nuestras resistencias a jugar.

La segunda, El carnaval y la fiesta como experiencia educativa. Dentro de la experiencia educativa con jóvenes del programa de recreación han sido varios los puntos que se han ido construyendo: a) reconocer el lugar que la fiesta ha ocupado en su experiencia de vida. En la revisión de este aspecto podemos encontrar la experiencia festiva como algo central en la construcción de los sujetos, en la construcción de vínculos con otros o como algo marginal, algo de lo cual no se tuvo acceso en su historia familiar, escolar, etc. Este lugar marca una relación importante como la construcción de socialidades, los usos y miradas frente al cuerpo, la danza, la música, etc; b) reaprender a reírnos de nosotros mismos, una de las tareas de disciplinamiento del cuerpo (Foucault, 2002) consiste en darle un carácter oficial a nuestra manera de concebir el mundo; esto implica que la risa como experiencia expresiva se contiene o se le ha dado un carácter de ridiculización del otro en el que me abstraigo y me burlo.

Desde los principios del carnaval revisados en este artículo, una de las tareas de formación consiste en aprendernos a reír colectivamente no como una forma alienante hacia el otro sino como una forma creativa y liberadora entre todos. 
El principio educativo aquí es "todos nos reímos de todos"; c) el reconocimiento estético, histórico y político en el que emergen los carnavales. Una revisión de la estética implica comprender cómo el pueblo concibe esta idea-mundo. Poder estudiar también cómo la fiesta y el carnaval son una expresión también de disputas y tensiones entre el mundo oficial y el mundo no oficial. Los carnavales no sólo construyen una vida paralela sino que también en el juego, en la máscara, en el disfraz, sus actores se disputan la historia, la organización y dinámica de los procesos festivos, las miradas del mundo y lo social.

Aquí, es clave entonces entender cómo el carnaval no es un "mundo feliz" sino un mundo en el que hay tensiones y disputas que son reactualizadas; d) la posibilidad de comprender el papel que cumple el disfraz, la música y la máscara como elementos expresivos, como lenguajes en los que se puede potencializar la imaginación y la creatividad; e) el curso Historia de la Recreación II propone una serie de tareas del orden de lo metodológico y lo vivencial que le apuestan a que el estudiante tenga un repertorio de maneras de cómo generar procesos de intervención desde la fiesta y comprender cómo estos elementos expuestos en este artículo ocurren en la vivencia de la fiesta y en un trabajo reflexivo sobre ella.

Un trabajo importante en la formación de profesionales en recreación ha sido un énfasis sobre el trabajo etnográfico. En algunas versiones del curso se ha realizado un reconocimiento de algunas festividades y formas de encuentro a nivel local y regional. La idea es seguir fortaleciendo este trabajo y apostarle a un mapeo detallado de estas expresiones festivas. Aquí es clave la noción de Etnografía Multilocal propuesta por Marcus (2001), quien considera que existen distintas modalidades o técnicas de rastrear los modos de asociación, conexión y circulación de los fenómenos culturales, entre las que se encuentran el seguimiento de las personas y sus biografías, seguir las obras o las metáforas. Desde esta propuesta lo que se examina es la circulación de significados, objetos e identidades culturales en su tiempo determinado. La idea central es que la etnografía multilocal permite rastrear las experiencias como lugares de confluencia dinámica entre lo local y lo global.

La tercera, como laboratorio de formación. El Programa de Recreación, cuenta con su laboratorio como espacio físico en el que se materializan procesos de Diseño y Creación, se apoya la docencia en el componente de Lenguajes Lúdica Creativos, pero también es un proyecto de creación y reflexión.

En cuanto a la investigación, se encuentra en fase de estudio de publicación el libro El Diablo está de fiesta. La Cuadrilla del Carnaval de Riosucio: sus poéticas y políticas de la amistad (Henao \& Sánchez 2019) derivado del Informe de Investigación: La dimensión educativa del Carnaval de Riosucio-Caldas: una lectura desde sus formas organizativas y recreativas (Henao et al, 2019). A nivel de dirección de trabajos de grados se encuentra en fase de diseño el proyecto de pregrado "Arte/Juego: El Carnaval de Riosucio como escenario estético y de juego” (Girón, 2019). Y como 


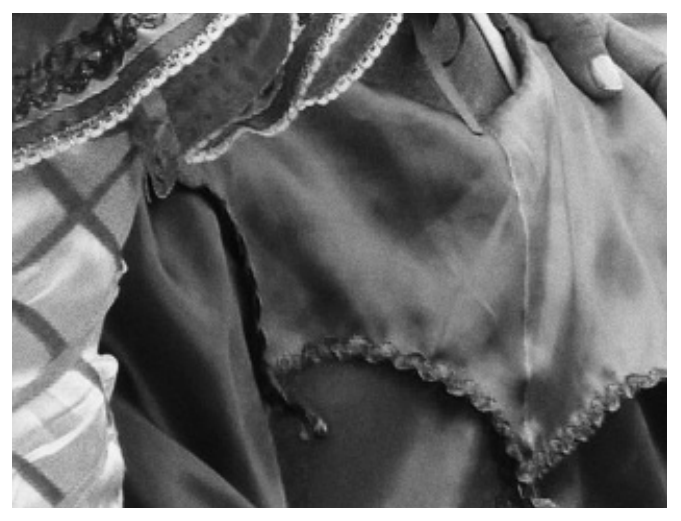

proyectos de grado terminados: un trabajo de maestría para optar al título de Magíster en Educación, Énfasis en Educación Popular y Desarrollo Comunitario. La fiesta de la Virgen del Carmen en Acandí-Chocó: una mirada etnográfica a la fiesta como proceso organizativo y educativo (Sánchez, 2016) y un trabajo de pregrado para optar al título de Profesional en Recreación: "Reflexiones sobre la formación en investigación en el programa académico de recreación de la Universidad delValle: una mirada auto-etnográfica desde el Carnaval de Riosucio 2013” (Cárdenas, 2014).

En cuanto a la extensión un espacio importante en el que este ejercicio de lo festivo tuvo gran acogida fue durante los meses de octubre y noviembre de 2011 en el marco del Paro Nacional de Universidades Públicas en Colombia a causa de la Reforma a la Ley 30 de Educación Superior. Los estudiantes de Recreación realizaron propuestas abiertas en la que aplicaron y enseñaron algunas nociones de lo festivo: trabajaron el diseño de máscaras, propusieron la noche roja en el marco de la Noche de Carnaval y Besatón en Univalle, acudieron a las marchas ofreciendo una estética distinta desde el disfraz, ofreciendo cánticos distintos a las arengas tradicionales. Recordemos que este fenómeno festivo y carnavalesco fue uno de los elementos comunes a nivel nacional y que puso una mirada distinta sobre las formas de protesta y movilización del movimiento estudiantil a nivel nacional. En los años 2012 y 2013, se acompañaron dos cursos de corta duración de Extensión Extracurricular en la Universidad del Trabajo de Uruguay denominado "Desarrollo y potenciación de las capacidades docentes, investigativas y de intervención social en el campo de la recreación". Dentro del marco de este trabajo se propuso la estrategia "Carnavalito", diseñada por la profesora Guillermina Mesa, en la que se aprovechó la memoria y riqueza estética de los uruguayos y su carnaval a través de las murgas de carnaval. En el año 2017, dos integrantes de la línea de Recreación, Intersubjetividades e Interculturalidad se vincularon al proyecto de Extensión "Mi comunidad es Escuela", liderado la Universidad del Valle y financiado por la Alcaldía Municipal de Cali. En su rol de Coordinadores del proyecto Competencias Básicas diseñaron una propuesta festiva para el Instituto de Educación y para la Facultad de Artes Integradas denominada: "Sincronía, fiesta y vida" que tenía como propósitos: a) entrar a las 45 IEO vinculadas a esta estrategia educativa implementada en la ciudad de Cali, aprovechando la alegría y gramática de las fiesta de fin de año, teniendo en cuenta las coyunturas educativas presentadas en ese año debido al Paro de Maestros, b) realizar un balance (diagnóstico) festivo y participativo con las IEO sobre sus Proyectos Pedagógicos Transversales, la relación Familia-Escuela, los Proyectos de Servicio Social (PSS) y las experiencias artísticas promovidas desde la escuela -Ejes de trabajo del Proyectopara visualizar propósitos y líneas de acompañamiento pedagógico para el próximo año (2018); año en que la Universidad del Valle empezaría la implementación del proyecto (Giraldo, Henao \& Sánchez, 2017). 
El Grupo de Estudio Nómadas, emerge en el año 2008, como resultado de estas búsquedas de formación en el campo de lo festivo y el turismo. Con el Grupo se ha diseñado rutas de viaje a los Carnavales de San Juan de Pasto (2008, 2012 y 2014), Festival Iberoamericano de Teatro (2008, 2012 y 2014) Carnaval de Barranquilla (2010 y 2015), Carnaval de Riosucio (2009, 2011 y 2013). Nómadas, también ha estado a cargo desde el año 2013 de las Bienvenidas de Estudiantes de la Facultad de Artes Integradas (FAI) de la Universidad del Valle, integrando dentro de sus propuestas, espacios festivos/rituales mediante la construcción de máscaras de carnaval y comparsas. Procesos que posibilitan el reconocimiento y creación de vínculos entre los estudiantes que ingresan a primer semestre. En la actualidad, estos trabajos han llevado a pensar el carnaval y el viaje como espacios de producción de conocimiento. Por ejemplo, la investigación de los profesores Diana Lorena Sánchez ${ }^{12}$ y Armando Henao ${ }^{13}$ sobre el Carnaval de Riosucio posibilitó que se integraran al diseño y creación de una cuadrilla de carnaval, siendo cuadrilleros en las versiones del Carnaval de Riosucio 2015 y 2019.

Para finalizar es importante plantear que este es uno de los enfoques posibles desde los cuales abordar lo festivo como campo de formación. Pensar lo festivo como un fenómeno que al igual que el juego se aprende y se enseña; por esta razón requiere de actores e instituciones que también puedan interlocutar con estas experiencias festivas, problematizar las estéticas, los sentidos y lugares de la fiesta en la construcción de sujetos comprometidos con la creatividad, con el goce colectivo y estético, en la construcción de país y el reconocimiento de nuestra riqueza y diversidad cultural a la hora de dotar de sentido la vida, celebrarla y ritualizarla. 


\section{Notas}

1 Profesional en Recreación. Magíster en Educación Popular y Desarrollo Comunitario. Profesordel Instituto de Educación y Pedagogía de la Universidad del Valle. Trabaja con los ProgramasAcadémicos de pregrado de Profesional y Tecnología en Recreación, Licenciatura en Educación Popular y la Maestría en Educación, Énfasis en Educación Popular y Desarrollo Comunitario. Director del Grupo de investigación en Educación Popular y coordinador de la línea de investigación Recreación, Intersubjetividades e Interculturalidad.

2 Este ejercicio docente inició para el profesor Armando Henao en el año 2006 como asistente de docencia, continuó en el año 2008 como profesor ocasional tiempo completo. En el año 2011, como parte de los compromisos durante el año de prueba, como profesor nombrado, se hizo la restructuración del curso Historia de la Recreación II. A partir del año 2016 el curso ha estado a cargo de dos profesores como parte de la estrategia metodológica para poder acompañar las distintas tareas de diseño y creación que se le proponen a los estudiantes en este curso. Es así, como algunas de estas tareas, también son el resultado de procesos de discusión, negociación, diseño y creación entre el profesor Armando Henao y la profesora Diana Lorena Sánchez Rico.

${ }^{3}$ Los estudiantes cuentan durante su formación con distintos campos de estudio entre los que se encuentran lo lúdico, lo festivo, lo contemplativo y los lenguajes lúdico creativos (Mesa, 1997).

${ }^{4}$ Ver trabajo de grado Erika Natalia Toro Valencia: "El grupo de Estudio Nómadas una experiencia significativa de formación a nivel personal y profesional para los estudiantes del Programa Académico de Recreación” 2014. Ver trabajo de grado Angélica María Londoño González "Reflexiones sobre el proceso organizativo del Nudo de Comunicaciones en el marco de la Salida Académica Carnaval de Negros y Blancos San Juan de Pasto 2012” 2018.

${ }^{5}$ El proyecto estuvo a cargo del profesor Armando Henao Velarde, como investigador principal. Como equipo de investigación estuvieron a cargo: Diana Sánchez, Juan Gabriel Arcila, Nathalia Cárdenas, Arley González. Este proyecto fue financiado con recursos de la Convocatoria Interna de Investigación 2012-1 de la Universidad del Valle.

${ }^{6}$ Este tema de la inversión se puede pensar, por ejemplo, en el cambio de ropajes entre hombres y mujeres durante los carnavales. Aquí los hombres se burlan de su masculinidad, del hecho de ser hombres y se disfrazan de mujeres, las tetas cambian de lugar y ocurren en la frente, en la espalda, en una rodilla, un falo es subido a un lugar significativo en el rostro. En este proceso de inversión todo lo que es ocultado cobra centralidad en el carnaval a través del disfraz, del juego y la estética. Ocurrecon La Marimonda del Carnaval de Barranquilla, el rostro al cual en la cotidianidad le damos mucha importancia, lo maquillamos para que se vea bonito, lo cuidamos, lo mostramos con orgullo, en el carnaval es dotado con formas que se asemejan a un gran falo, que hace las veces de nariz y testículos que hacen las veces de ojos. Es decir, pene y testículos, que cotidianamente están ocultos de manera calculada, son puestos en el carnaval en un lugar privilegiado, se juega, se burla de esto.

${ }^{7}$ Una de las escenas de la película Alicia en el País de las Maravillas de Tim Burton, recrea muy bien este paso entre el mundo oficial al mundo fantástico, el cambio de ropajes y la idea de inversión. En esta escena Alicia debe atravesar una diminuta puerta y su estatura (del mundo oficial) no le permite acceder al otro mundo, por lo cual ella requiere tomar una pasta que la reduce de tamaño, le hace abandonar sus ropas porque le quedan grandes y se introduce en la lógica de este otro mundo (no oficial, fantasioso, mágico).

${ }^{8}$ En el caso del autor del presente artículo fue la experiencia de diseñar viajes a carnavales y no su experiencia como docente enseñando lo festivo lo que lo llevó a pensar un ejercicio de diseño y creación de proyectos en torno a educación, recreación, fiesta y carnaval (Henao \& Sánchez, 2019).

${ }^{9}$ En el Carnaval de Barranquilla, la "Batalla de Flores" tiene sus orígenes en el regreso de los 
combatientes de la Guerra de los Mil Días. Cuando los soldados regresaron, el pueblo propuso una guerra, pero una guerra que exaltara la paz, la libertad, entonces propusieron una "Batalla", pero cambiar las balas por flores, se propuso "una Batalla de Flores". El Carnaval de San Juan de Pasto tiene como juego tradicional el juego con agua, harina o talco blanco, y la tradicional pinta negra. Con este ejercicio, pintarse de blancos, bañarse, pintarse de negros, recuerdan las distintas formas de pensar del pueblo, la fusión entre lo indígena-negro y lo blanco. El acto de un día pintarse de negro es una exaltación de la raza negra. El acto de pintarse de blanco es recordar el mundo hispano y su fusión. El agua, tirarse agua es una manera de tener guerras campales para liberar el espíritu combativo y festivo. Es decir, las batallas, las guerras del mundo OFICIAL, son representadas, recreadas y jugadas en el Carnaval a través de flores, de agua, de espuma de carnaval, de talco blanco, de pintura negra. En el caso del Carnaval de Riosucio, su elemento de juego ocurre través de la preparación de espectaculares disfraces, la elaboración de cuadrillas que cantan y se burlan del mundo oficial. La historia del Carnaval de Riosucio, expresa la fiesta que hubo que inventarse para que un pueblo decidiera juntarse. El juego, el disfraz y la máscara se convierten en lenguajes que entran a estructurar la propuesta festiva de los Carnavales.

${ }^{10}$ Este ejercicio de Bandas Gráficas es una técnica de trabajo propuesta por la profesora Guillermina Mesa, gestora del Programa de Recreación de la Universidad del Valle; quien construyó y lideró un espacio de formación con estudiantes y profesores en el marco del Proyecto Tejer desde Adentro: La Universidad Imaginada. En esta banda gráfica se propone al estudiante seleccionar y graficar seis momentos significativos de su experiencia y vínculos con lo festivo.

${ }^{11}$ Este proceso de descargas visuales ha sido aprendido en el proceso de acompañamiento de cursos y trabajo de extensión en recreación con la profesora Guillermina Mesa y el Equipo de Trabajo en la Línea de Investigación en Recreación, Intersubjetividad e Interculturalidad y del Proyecto Tejer desde Adentro. Las descargas visuales sirven como "fuentes de inspiración" para el trabajo de diseño, partiendo de que la creatividad no parte de un punto cero, sino que es un proceso de resignificación, capacidad combinatoria y adecuación de experiencias y saberes acumulados. La descarga busca problematizar, mostrar posibilidades de resolver la tarea.

${ }^{12}$ Integrante de La Cuadrilla Delirio Pagano (2019). Carnaval de Riosucio 2019.

${ }^{13}$ Integrante de La Cuadrilla ElViacrucis de Colombia (2015). Carnaval de Riosucio 2015. Integrante de La Cuadrilla Delirio Pagano (2019). Carnaval de Riosucio 2019.

\section{Bibliografía}

Bajtin, M. (1990). La cultura popular en la Edad Media y en el Renacimiento. El contexto de François Rabelais. (J. Forcat, \& C. Conroy, Trads.) Madrid: Alianza Editorial.

Barbero, J. (1987). De los medios a las mediaciones. Comunicación, cultura y hegemonía. México: Gustavo Gili.

Bourdieu, P. (1991). El sentido práctico. Madrid: Taurus.

Cardenas, N. (2014). Reflexiones sobre la formación en investigación en el programa académico de recreación de la Universidad del Valle: una mirada auto-etnográfica desde el Carnaval de Riosucio 2013. Cali: Universidad del Valle.

Coll, C. (1985). Acción, interacción y construcción del conocimiento en situaciones educativa. Universitat de Barcelona.

Coll, C. (1988). Significado y sentido en el aprendizaje escolar. Reflexiones en torno al concepto de aprendizaje significativo. Revista Infancia y aprendizaje.

De Certeau, M. (2000). La invención de lo cotidiano. I.Artes de hacer. México: Universidad Iberoamericana. Departamento de Historia. Instituto Tecnológico y de Estudios Superiores de Occidente.

Foucault, M. (2002). Vigilar y Castigar. Nacimiento de la prisión. Buenos Aires: Siglo Veintiuno Editores. 
Giraldo, D., Henao, A., \& Sánchez, D. (2017). Propuesta de Diseño Conjunto Entrada Festiva en 45 IEO de la ciudad de Cali: Sincronía, Fiesta y Vida. Cali: Universidad del Valle.

Goffman, E. (1959). La presentación de la persona en la vida cotidiana. . Buenos Aires : Amorrortu.

Gómez, R. \& Gónzalez, Julián. (12 de Agosto de 2005). La dimensión recreativa de la educación popular y de adultos: la imaginación como desafío educativo y político. Debate en Educación de Adultos, Año 12 (19).

Gónzalez, J. (1999). (Auto) Biografías Públicas en Educación Popular. Revista de La Universidad Popular, 24-46.

Gónzalez, J. (2000). Curso de estrategias de comunicación popular. Cali: Universidad del Valle.

Henao, A. \&. (2019). El diablo está de fiesta. La Cuadrilla del Carnaval de Riosucio: sus poéticas y politicas de la amistad. Cali: Sin publicar.

Henao, A. (2008). Guía de Trabajo. Auto Biografías Festivas. Curso Historia de la Recreación II. Cali: Sin Publicar.

Henao, A. (2012a). Recreación/Fiesta y Educación: un estudio del carnaval de Riosucio como experiencia recreativa y organizativa. Cali: Sin publicar.

Marcus, G. (2001). Etnografía en / del sistema mundo. El surgimiento de la etnografía multilocal. (M. Aguilar, Trad.) Universidad Autónoma Metropolitana, Unidad Iztapala: Alteridades, 2001-11-22.

Maffesoli, M. (1996). The times of the tribes: The Decline of Individualism in Mass Society.

Mesa, G. \&. (2008). La Recreación dirigida: un laboratorio pedagógico para contemplación activa y creativa de la televisión. Cali: Comisión Nacional de Televisión y Universidad del Valle.

Mesa, G. (1997). La Recreación Dirigida como proceso educativo. Barcelona: Departamento de Psicología Evolutiva y de la Educación Universidad de Barcelona.

Mesa, G. (9 de 2004). La Recreación “Dirigida”: ¿ mediación semiótica y práctica pedagógica?-Una pregunta para el debate. Santiago de Cali, Colombia: Universidad del Valle.

Mesa, G. (2005). Programa Académico de Recreación. Proyecto Educativo en el marco del acuerdo $N^{\circ} 009$ del Consejo Superior de la Universidad Mayo 26 de 2000. Cali: Universidad del Valle, Instituto de Educación y Pedagogía, Área de Educación, Desarrollo y Comunidad.

Mesa, G. (2008). La recreación dirigida como práctica pedagógica. Cali: Documento sin publicar.

Mesa, G. e. (2011). La Recreación como una estrategia pedagógica para reiventar la fiesta. Ponencia presentada en el Encuentro sobre estudios de fiesta, nación y cultura organizado por la Red Internacional de Investigadores en Estudios de Fiesta, Nación y Cultura-RIEF- Bogotá Abril de 2011, Bogotá.

Pizano, O., Zuleta, L., Jaramillo, L., \& Rey, G. (2004). La fiesta, la otra cara del patrimonio. Valoración de su impacto económico, cultural y social. Colombia: Economía \& Cultura.

Sánchez, D. (2016). La fiesta de laVirgen del Carmen en Acandí-Chocó: una mirada etnográfica a la fiesta como proceso organizativo y educativo. Cali: Universidad del Valle.

Yudice, G. (2002). El recurso de la cultura. Usos de la cultura en la era global. Barcelona: Gedisa.

Recibido: 3 de Mayo de 2019 / Aprobado: 30 de Mayo de 2019

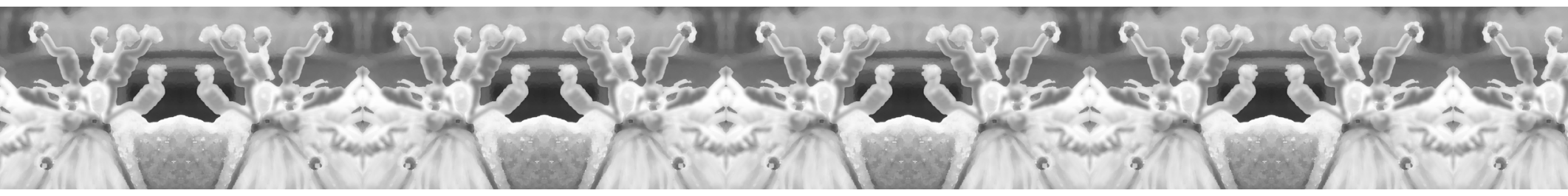

